DOI https://doi.org/10.18551/rjoas.2018-11.07

\title{
THE IMPACT OF THE ENTREPRENEURIAL ECOSYSTEM ON REGIONAL COMPETITIVE ADVANTAGE: A NETWORK THEORY PERSPECTIVE
}

\author{
Purbasari Ratih*, Wijaya Chandra \\ Faculty of Administration Science, Department of Business Administration, \\ University of Indonesia, Depok, West Java, Indonesia \\ Rahayu Ning \\ Faculty of Administration Science, Department of Fiscal (Tax) Administration, \\ University of Indonesia, Depok, West Java, Indonesia \\ ${ }^{*}$ E-mail: ketik.ratih@gmail.com. \\ ORCID: 0000-0003-0947-7617
}

\begin{abstract}
Regional competitive advantage is pivotal in supporting global competitiveness. An entrepreneurial ecosystem is believed to promote competitive advantage; however, the process of how it helps build regional conditions favorable to a specific economic activity remains unexplained. Some experts have generated models of entrepreneurial ecosystems, but these exemplars do not describe the interaction and associations between the elements within the ecosystem. This study aims to formulate a few basic theoretical statements pertaining to the impact of the entrepreneurial ecosystem on the competitive advantage of a region. This study also aims to create a conceptual model of how entrepreneurial ecosystems may be linked to regional competitive advantage. This paper proposes a theory and presents a review of extant literature to develop the concept of pertinent variables. The network theory perspective is employed as an analytical approach to determine the working of the mechanism within an entrepreneurial ecosystem that subsequently affects a region's competitiveness. The entrepreneurial ecosystem model posited in this paper indicates the unique and differentiated conditions of entrepreneurial ecosystems that grow in particular locations. It is theorized that the entrepreneurial ecosystem will influence regional competitive advantage through mechanisms such as knowledge transfer, productive entrepreneurship, and innovation. The entrepreneurial ecosystem model mooted by this paper can be used to formulate regional economic development policy.
\end{abstract}

\section{KEY WORDS}

Entrepreneurial ecosystem, regional competitive advantage, network, network theory, competitive advantage, entrepreneurship.

Policy makers, NGOs, and business enterprises have discussed competitiveness and entrepreneurship for a long time (Rodriguez, E Soto, 2015). Porter (1990) states that entrepreneurship is "at the heart of national advantage" (Carree MA \& Thurik AR, 2010). In addition, entrepreneurship is regarded as the process of recognizing, building, and pursuing opportunities to create value through innovation (Churchill, 1992; Roudy, 2017). It is also viewed as a fundamental component of emerging economies (Acs, Desai, \& Hessels, 2008; Wong, Ho, \& Autio, 2005; Roudy, 2017) that drives fiscal growth, development, and prosperity (e.g., Acs et al., 2008; Roundy, 2017). Entrepreneurship activities increase labor market fluidity (Evans, 1989; Roudy, 2017), and they are also associated with job creation (Folster, 2000; Roudy, 2017) and the introduction of innovative products and services (Schumpeter, 1934; Roudy, 2017). In all these courses of action, entrepreneurship results from the interaction between individual attributes and the surrounding environment (Stam, $E$ \& Bosma, N, 2015; Acs., ZJ, Stam, E., Audretsch, DB, \& O'Connor, A, 2017).

The entrepreneurial ecosystem comprises both cooperation and competition among companies, sectors, industries, linking organizations, technologies, consumers, and products 
(Anggraeni, Den Hartigh, \& Zegveld, 2007; Adao Flores, Elsa Pereira, \& Henrique Graca, 2017). This network of relationships involves varied actors and their exchanges as they contribute to the productive performance of a community or territory (Spilling, 1996), providing opportunities for new businesses, illustrating the limits of commercial achievement (Thornton, Ribeiro-Soriano, \& Urbano, 2011; Welter, 2011), and facilitating the sustainability of the entrepreneurial environment itself (Cohen, 2006; Adao Flores, Elsa Pereira, \& Henrique Graca, 2017).

Furthermore, the entrepreneurial ecosystem is composed of a network arrangement that is useful for the development of policies that support competition (Isenberg, 2010). This approach encompasses the potential to "replace" or even provide the requisite initial conditions for cluster strategies, innovation systems, knowledge-based economies, and national competitiveness policies (Isenberg, D, 2011). Several empirical studies have demonstrated the ways in which superior entrepreneurial ecosystems enable the creation of enterprise quality and the development of competitive values at the regional level (Fritsch, 2013; Tsvetkova, 2015).

The current guidelines for SME and entrepreneurship development emphasize the increase in competition, job creation, and fiscal growth, while public policy highlights creativity, innovation, and economic progress (Storey \& Stevenson, 2005; Rodriguez, E Soto, 2015). The entrepreneurial ecosystem approach can be employed to support such efforts because the environment consists of various actor networks, and the collaborative roles played by these actors can bolster competitive advantage both on the global or local scale. Barney (2001) argues that continuous competitive advantage attained by the application of a strategy to achieve unique values will contribute to competitive success in a dynamic industry environment. In the process of the realization of competitive advantage, the emphasis has shifted to small local-based producers acting collaboratively on long-term growth, as well as on the upgrading of sustainable standards. The economic success and viability of an industry or a region is now seen to stem from policymaking that is aimed at developing networks among producers in order to enhance competitiveness and to inculcate local economic activities (Mike Raco, 1999). Thus, competitive advantage can be vested at firm, regional, and even national levels by escalating the direct and indirect capabilities of a company, area, or nation to produce intensive knowledge, improve productivity, increase innovation, and to build corporate entities that integrate local and global value chains (Cooke, P, 2016).

However, scholarly activity on entrepreneurial ecosystems is still lacking in certain respects. The absence of previous theories and research on the impact of the entrepreneurial ecosystem vis-à-vis the superiority of a region's competitiveness is a case in point: no explanation exists on the manner in which an entrepreneurial ecosystem can build a regional competitive edge. Models of the entrepreneurial ecosystem generated by a few experts lack the causal path, do not describe the interaction or associations between the elements of the ecosystem, and are unclear in the analysis of the entrepreneurial ecosystem methodology (Isenberg, 2011: Mason \& Brown, 2014; Stam, 2015; Jennen Tina et al., 2016). Moreover, extant scholarship pertaining both to the ecosystem strategy and to regional development primarily spotlights the role of entrepreneurs in creating value (Pitelis, 2012; Stam \& Spigel, 2016). Stam and Spiegel (2016) assert that the notion of entrepreneurial ecosystems represents a shift from entrepreneurship policies (quantity) to entrepreneurial economics (quality). Employing the ecosystem approach to improve the quality of entrepreneurship is expected to address the challenges of regional economic development, as well as increase local competitiveness. Thus, it is necessary to devise a concept that delineates the role of entrepreneurship and the manner in which its interaction with other actors within the entrepreneurial ecosystem affects regional competitiveness.

This study aims to formulate a few basic theoretical statements pertaining to the impact of the entrepreneurial ecosystem on the competitive advantage of a region. It also attempts to establish a conceptual model of entrepreneurial ecosystems. The network theory perspective is employed as an analytical approach to determine the working of the mechanism within an entrepreneurial ecosystem that subsequently affects a region's competitiveness. The network theory helps to elucidate the interactions between actors and 
factors that occur within the entrepreneurial ecosystem in the context of knowledge transfer, productive entrepreneurship, and innovation.

Entrepreneurial Ecosystem. The concept of an ecosystem originates in biology. The term refers to the natural environment and its elements, including the living organisms (biotic factors) in an area as well as the physical environment (abiotic factors), which function together as a unit. Roy Clapham (1930) originally coined the word to demonstrate the physical and biological components of an environment that formed a unified whole (Nicotra, $\mathrm{M}$, et al., 2017). This notion of ecosystems has been adopted into the perspective of the business environment (Moore, 1993), with specific reference to entrepreneurial networks. To succeed in the current competitive environment, companies must become components of an ecosystem where they jointly develop skills, innovate, and evolve. In this sense, ecosystems are slowly transforming in both business and natural terms from a confused collection to systems with structured elements. Moore (1993) affirms that ecosystems symbolize a response to the need for the promotion of innovation and creativity in the process of determining answers to economic and social issues. The concept of an ecosystem as it is applied to entrepreneurship goes beyond the development of an inter-entrepreneur network structure. The notion encompasses the capacity of a region to create an actor and infrastructure arrangement that supports the construction and development of pioneering business activities (Nicotra, M, et al., 2017).

Acs et al. (2017) explain that the entrepreneurial ecosystem approach contains two dominant directions: strategic scholarship and regional development research. Both branches are conceptually rooted in the notion of the ecological system, and both stem from the interdependence of actors within a particular community to create new values. In the literature that emphasizes strategy, emerging perspectives conceive of the business ecosystem as a form of economic coordination in which a company's ability to create decent value depends on the various groups of actors who produce complementary products or services (lansiti \& Levien, 2004; Adner \& Kapoor, 2010; Williamson \& De Meyer, 2012; Acs et al., 2017). The business ecosystem refers to a set of partners who must be aligned in a manner that aids the materialization of value bidding in the market (Adner, 2017). Alternatively, research articles accentuating regional development highlight area-specific ecosystems in accordance with the distinctive socioeconomic performance of each territory. This literature comprises concepts such as industrial clusters, provincial industrial zones, and regional innovation systems (Stam \& Spigel, 2017; Terjesen et al., 2017; Acs et al., 2017). The cluster approach focuses on the geographical concentrations of interconnected firms, specialized suppliers, service providers, companies in related industries, and related institutions in specific areas that compete against each other but also work together (Porter, 1990). The regional industrial area methodology emphasizes the local industrial workforce (Marshall, 1920) and the interactions between human agencies and corporate entities within a specific socio-territorial community (Becattini, 1990) given the objective of succeeding in international markets. The regional innovation system method refers to networks and institutions that link knowledge centers, such as universities and public research laboratories, with innovative companies within a region (Acs et al., 2017).

Therefore, the entrepreneurial ecosystem may be regarded as a set of interdependent factors that are coordinated in a manner that encourages the emergence of entrepreneurship. These factors are related to the availability of actual and potential knowledge, the presence of investors, human resources, culture, infrastructure, institutions, regulations and fiscal conditions, social and environmental quality, and the ability to generate innovation (Nicotra, M, et al., 2017). Mason and Brown (2014) describe the entrepreneurial ecosystem as a set of relationships among entrepreneurs, entrepreneurial organizations, entrepreneurial institutions, and entities that formally and informally merge to interconnect, mediate, and regulate entrepreneurial performance within the local entrepreneurial environment. The entrepreneurial ecosystem is thus dynamic and systemic, involving many actors, institutions, and processes. Alternately, Erik Stam (2015) defines an entrepreneurial ecosystem as a set of actors combined with related and coordinated factors that together produce productive entrepreneurship. 
Isenberg (2011) identifies six elements of the entrepreneurial ecosystem: policy, finance, culture, support, human, and market resources. The key to sustainable entrepreneurship lies in the specific arrangement of elements in the entrepreneurial ecosystem (Isenberg, 2010; 2011). Mack and Mayer (2016) confirm that the concept of entrepreneurial ecosystems is essential to the formation of new companies and for the support of local entrepreneurial activities. Thus, entrepreneurial ecosystems can understandably bolster regional competitive advantages gained through knowledge and innovation by increasing value creation through local commercial activities.

Competitive Advantage. Gaining a global advantage over rivals in particular specializations is the main economic goal of governments across the world (Porter, 1990). This worldwide competitiveness is influenced by many factors; however, innovation in scientific discovery and the creation of new technologies have been commonly recognized as two of its main drivers (Cameron, 1996; Hall \& Jones, 1999; Freeman, 2002; Rosenberg, 2004; Wang et al., 2007; Gibson \& Naquin, 2011; Krammer \& Sorin M. S, 2017). This argument aligns with Porter's viewpoint (1990) that competitiveness is a function of dynamic progression, innovation, and the ability to change and increase value. Porter (1990) further explains that the only meaningful concept of competitiveness pertains to productivity in utilizing a country's resources. A nation's standard of living is determined by its economic productivity as measured by the value of goods and services produced per unit of human resources, capital, and non-human assets. In this sense, competitive advantage is created and maintained through a highly local process (Porter, 1990, p. 19; Kitson et al., 2005; Castilla-Polo et al., 2017).

In today's global economy, the region is increasingly considered an important source of economic and organizational development (Scott, 1995; Cooke, 1997; Amin, 1999; Werker \& Athreye, 2004; Malecki, 2007). Cellini and Soci (2002) contend that the idea of regional competitive advantage is encased in macroeconomic (national) or microeconomic (corporate-based) (Kitson et al., 2005; F. Castilla-Polo et al., 2017) contexts. Regional competitiveness refers to conditions that enable companies to compete in their chosen markets, and the value-generation that is contributed to a region by such enterprises (Begg, 1999; Huggins, 2003; Kitson et al., 2005; F. Castilla-Polo et al., 2017). The entrepreneur's role of administering a company that can create value then becomes vital. Regions that can claim institutions and cultures that are conducive to entrepreneurship can enhance their competitive advantages by attracting investments, skills, and talent (Turok, 2004; Robert Huggins \& Nick Williams, 2011). Culture shapes the phenomena viewed by individuals as opportunities; therefore, entrepreneurial attention is drawn by the judgment, creativity, and interpretation of business opportunities (Hofstede, 1991; Lavoie, 1991; Verheul et al. 2001; Sautet \& Kirzner, 2006; Huggins, Robert and Williams, Nick, 2011). Areas invested with a strong entrepreneurial culture gain a competitive advantage if they are able to develop this pioneering mindset and generate novel concepts from time to time (Audretsch \& Fritsch, 2002; Parker, 2004; Mueller, 2006; Huggins, Robert and Williams, Nick, 2011). As a valuable part of entrepreneurial capital, culture refers to the capacity of a society to generate and to build on its entrepreneurial activities to create a positive impact on regional economic performance (Audretsch \& Keilbach, 2004; Huggins, Robert and Williams, Nick, 2011).

Network Theory. Networks frequently express a pattern of "co-opetition," reflecting a specific balance between cooperation and competition. Intra-network and internetwork relations are founded on a mix of collaboration and opposition (Carayannis E.G. \& Campbell D.F.J, 2011). A network consists of a set of actors or shared nodes in an array of certain types of bonding such as friendship or business (Boggati \& Halgin, 2011).

An ecosystem consists of discrete elements that interact with different network configurations. According to Letaifa (2013, p. 88; Letaifa et al., 2016), "ecosystems are an extension of network theory." Network theory may be utilized to describe relationships between organizations that have common or complementary features that facilitate access to resources and information or to define the structures of social interaction among organizations. Jack (2010) considers that network theory has become a key element of entrepreneurial research. The network approach and strategic thinking are suitable means of 
exploring the relationships and interdependence of ecosystem actors for value creation (Kapoor \& Lee, 2013; Zahra \& Nambisan, 2011; 2012).

The relational structure among different stakeholders in the entrepreneurial ecosystem is an aspect that is implicit in the network theory perspective, which explores the levels of connectivity between employers, government agencies, incubators, or members of accelerator organizations and investors or members of higher education organizations that influence social network connectivity (Xaver Neumeyer \& Susana C Santos, 2017). The basic measures to be employed include (Hanneman, Robert, A., \& Mark Riddle, 2005; Fritsch, Michael, Kauffeld-Monz, Martina, 2008; Xaver Neumeyer \& Susana C. Santos., 2017):

a. Network Size. The size of the network imposes restrictions on the structure of social relationships because of the limited resources and capacity of each actor to build and maintain relationships.

b. Cohesion. The proportion of all the bonds found in the network is computed using concepts such as density, attainability, and connectivity.

c. Centrality. This term refers to the nature of a social structure. The analysis of centrality in a social network can provide knowledge of the role played by an individual component in its environment. The implication of a central actor signifies a performer who has the strong ability to connect other players in the network.

d. Heterogeneity. The diversity of competencies/resources in a network is evidenced by the presence of varied partners within the structure having complementary sets of abilities.

e. Frequency of interaction. The intensity of the participants in an interaction is characterized by how often they interact with other actors within the network.

The Impact of an Entrepreneurial Ecosystem on Competitive Advantage. Entrepreneurial ecosystem scholars contend that regional advancements can be improved through the development of ecosystems; however, this effect may be moderated by entrepreneurial output. Certain conceptions of entrepreneurship reflect the multi-faceted nature of private enterprise (Acs et al., 2014; Wennekers \& Thurik, 1999; Szerb, Laszlo, Lafuente, Esteban, Horvath, Krisztina, Pager, \& Balazs, 2017). This requirement of versatility stems from the definition of entrepreneurship that emphasizes the utilization of opportunities through the creation of new ventures. In this sense, entrepreneurial activity pertains to the process of recognizing and exploiting valuable business opportunities (Kirzner, 1997; Shane, 2009; Vivarelli, 2013; Szerb, Laszlo, Lafuente, Esteban, Horvath, Krisztina, Pager, \& Balazs, 2017). Identifying and exploiting these business opportunities requires entrepreneurial knowledge and ability and is further related to the culture that shapes what the individual regards to be an opportunity. Hence, entrepreneurial attention is constantly related to the judgment, the creativity, and the ability of the entrepreneur to interpret business opportunity (Hofstede, 1991; Lavoie, 1991; Verheul et al., 2001; Sautet \& Kirzner, 2006; Huggins, Robert and Williams, Nick, 2011).

This study aims to use the network theory perspective to build a conceptual model of entrepreneurial ecosystems, particularly in relation to the notion of local competitive advantage. It has been proposed that entrepreneurial ecosystems impact the regional competitive advantage through mechanisms such as knowledge transfer, entrepreneurship productivity, and innovation. Figure 1 illustrates the associations established by Huggins (2013) between knowledge, innovation, and competitive advantage in a business enterprise. The figure explains that an enterprise must adapt and update its knowledge to maintain its competitive advantage (Redenmaker, 2005; Caiazza et al., 2015; Liao et al., 2016). This concept is reinforced by the definition that competitiveness is equivalent to a "high road of regional competition," where a specific territory can compete by seeking to achieve high levels of innovation, improvement, and growth (Malecki 2004; Huggins, Robert and Williams, Nick, 2011). Competitive advantage is increasingly concerned with creativity, knowledge, and environmental conditions, rather than purely on the basis of accumulated wealth (Huggins, 2003; 2013), and Drucker (1985) adds that in reality, businesses must consider knowledge to be the only source of commercial competitiveness (Liao et al., 2016). 
Transfer of Knowledge between Actors in the Entrepreneurial Ecosystem. In the current business environment, public policy tends to encourage the creation of an entrepreneurial ecosystem because it is believed to be a tool for the promotion of local development. This process requires information transfer because knowledge promotes innovation and economic growth (Adao Flores, Elsa Pereira, \& Henrique Graca, 2017). Davenport and Prusak (2000, p. 5) define the term knowledge as a "fluid mix of framed experience, values, contextual information, and expert insights that provide a framework for evaluating and incorporating new experiences and information." Additionally, Hall and Andriani (2002) describe knowledge as a combination of factors that possesses the potential to influence human thinking and behavior. Nonaka and Takeuchi (1995) introduce the concepts of explicit and tacit knowledge, analyzing the processes of comprehension in terms of interactions and influences between individual/group and organizational knowledge (Adao Flores, Elsa Pereira, \& Henrique Graca, 2017).

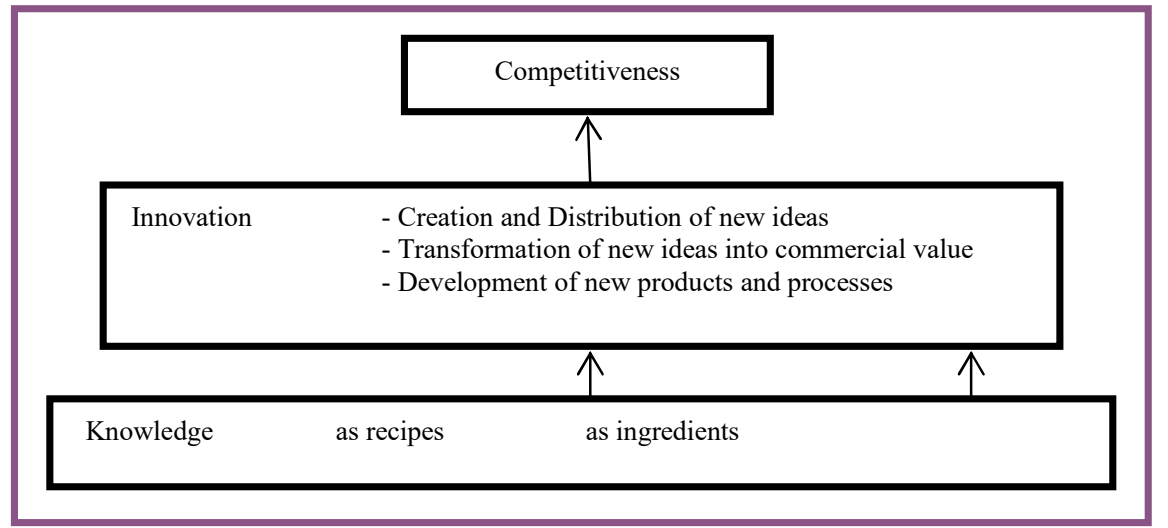

Figure 1 - The relationships between knowledge, innovation, and competitiveness in a business enterprise (Source: Huggins, Robert; 2013)

As a network, an entrepreneurial ecosystem is the product of a long evolutionary process that defines the relationships between industry players. This complex provides companies with resources, alliance partners, and important information regarding market conditions. Competing within an ecosystem requires the exigencies and adjustments of strategic thinking and free enterprise, and this process can create new knowledge to support further entrepreneurial activities and increased tactical thought (lansiti \& Levien, 2004; Nambisan \& Sawhney, 2007a; Zahra, SA \& Nambisan, S, 2012). Established companies and new ventures often play different, but complementary roles in an ecosystem. These functions require them to exploit certain areas of the ecosystem (Livingston, 2007) and this course further encourages fruitful co-productivity, which in turn enriches various other entrepreneurial activities within the ecosystem. Outputs and outcomes can be collapsed into the concept of productive entrepreneurship (Acs, Z.J., Stam, E., Audretsch, D.B., \& O'Connor, A, 2017).

Productive entrepreneurship is characterized by the creation and expansion of enterprises that embody elevated probabilities of success in the advancement of business and community life (Auerswald, Philip E, 2015). The notion of productive entrepreneurship (Baumol, 1990) leads to the definition of an entrepreneurial ecosystem as a set of actors and factors that are interconnected and coordinated in a manner that enables the creation of productive entrepreneurship within a specific area (Stam \& Spigel, 2017; Acs, ZJ, Stam, E., Audretsch, DB, \& O'Connor, A., 2017).

This argument suggests the following proposition:

P1. Knowledge transfers between actors in the entrepreneurial ecosystem can create productive entrepreneurship.

The Productive Entrepreneur and Innovation Systems. Entrepreneurship is pivotal to the innovation of the knowledge gained through its productivity. Productive entrepreneurship is manifested through entrepreneurial action to transform potential knowledge investments 
into other valuable forms (Hitt et al., 2001; Agarwal, Audretsch, \& Sarkar, 2007; R. Agarwal, D. Audretsch, \& M. Sarkar, 2010). Entrepreneurial action is a key element of the entrepreneurial process (Acs, Autio \& Sczerb, 2014) because it commonly produces innovation (Bird, Schjloedt, \& Baum, 2012; Diego Gazaro dos Santos, Aurora Carneiro Zen, \& Vitor Klein Schmidt, 2017). In addition, both the ecosystem strategy and regional development literatures recognize the functionality of entrepreneurs in creating value (Pitelis, 2012; Stam \& Spigel, 2017; Acs, ZJ, Stam, E., Audretsch, DB, \& O'Connor, A., 2017).

In value creation (and in the innovation process), entrepreneurship requires tasks to be performed by other actors within ecosystem. The ecosystem must consider the creation of a differentiated value proposition to attract not only the final consumer, but also the necessary partners. These actors may include several groups of stakeholder companies such as component suppliers, rival companies, auxiliaries, buyers, user communities, and universities. The need to manage the interactions and interdependencies among stakeholders thus arises (Uzunca et al., 2016; Acs, ZJ, Stam, E., Audretsch, DB, \& O'Connor, A, 2017). Given the need and existence of several actors involved in its processes, (universities, research institutes, business enterprises, government organizations, etc.), innovation should be regarded as an interactive progression, a network, and a collaboration (Zhang, 2013; Dubina, Igor N., et al., 2017).

Carayannis \& Campbell (2011) state that an innovation ecosystem that brings the perspective of the natural environment (social ecology) emphasizes the importance of diverse agencies, actors, and organizations, including universities. This innovation ecosystem consists of innovation arrangements that are part of the entrepreneurial ecosystem. According to Isenberg (2011), entrepreneurial ecosystems are potentially "prerequisites" for the successful implementation of the cluster strategy, the innovation system, the knowledge economy, or a national competitiveness policy (Isenberg, 2011).

This line of reasoning suggests the following proposition:

P2. The productive entrepreneur will encourage the ability to produce innovative goods and services. Eventually, the productive entrepreneur will contribute to the formation of the innovation structure within the entrepreneurial ecosystem.

Entrepreneurial Ecosystem and Competitive Advantage. The effects of increasing resource scarcity and competitive rivalry are being experienced by both developed and developing countries. Nearly all the areas of the world are connected in this era of information economy and the challenges of globalization are becoming increasingly real. Competitiveness is the key to success and survival in the given context. The ability to prevail over like rivals is not exhibited merely in the form of landing products in many homes, but also in terms of ameliorating quality. A superior product may be obtained by imaging or creating innovative merchandize that distinguishes itself from the goods manufactured in other regions (Salman, 2010; Nasir \& Yuslinaini, 2017). Carayannis and Campbell (2011) confirm that the key determinants of the efficacy and quantity of entrepreneurship and innovation unlock enterprise in the form of private, public, or hybrid goods. Qualified entrepreneurs are able to generate relatively high levels of job creation and productivity growth, and can competently produce and commercialize high-quality innovations (CM van Praag \& PH Versloot, 2007; Akbas, MI, Gunaratne, C., Garibay, OO, Garibay, I., \& O'Neal, T, 2015).

Pertinently, global value chains are becoming increasingly embedded in local value chains or clusters. Competitive advantages progressively invest in companies, regions, and countries that are adaptable to this new reality. Accordingly, this ability to adjust intensifies their direct and indirect capabilities to intensively produce knowledge, as well as to increase productivity, innovation, and the formation of new companies that accompany the integration of local and global value chains (Cooke, P, 2016). Audretsch and Pena-Legazkue (2012) assert that while innovation drives competitiveness and wealth, a prosperous region must also encompass a large number of local actors who support the transformation of innovative projects into phenomena of economic and social value through business creation. To a certain extent, the scale and quality of entrepreneurial capital depends on the policies designed and implemented by local governments that shape local commercial activities. The 
capacity of a region to derive positive benefits from entrepreneurship depends on its ability to transform knowledge into local growth through the creation and dissemination of information within its bounds (Audretsch \& Keilbach 2004; Huggins, Robert \& Williams, Nick, 2011).

To become capable of prevailing over its rivals and to inculcate a pioneering commercial culture, a nation requires public policy that capitalizes on the pillars of competitiveness and on the formation of an entrepreneurial ecosystem (Rodriguez, E Soto, 2015). Governments and business environments have acknowledged ecosystems as conceptual constructs that help enhance entrepreneurship and innovation (Acs, ZJ, Stam, E., Audretsch, DB, \& O'Connor, A, 2017). In addition, most of the results obtained from entrepreneurial ecosystem research are aligned to systemic literature on innovation systems (Borissenko \& Boschma, 2016). This affiliation applies particularly to aspects that highlight the relational elements between multi-actor networks within a governing region's entrepreneurship and its knowledge creation (Mason \& Brown, 2017). An ecosystem may be defined as a network of interconnected organizations connected to a focal firm or platform. This complex incorporates production and the use of side participants to create and appropriate new value through innovation (Autio \& Thomas, 2014; JJ Yun et al., 2017). By contrast, the term innovation system signifies related processes that underlie the development and transfer of knowledge (Freeman, 1995; Lundvall, 2010; Brown Ross \& Mason Colin, 2017).

The above rationale evokes the following proposition:

P3. The productive entrepreneur and the innovation structure of an entrepreneurial ecosystem can influence regional competitive advantage.

This proposition is supported by Fritsch (2013), who cites several empirical studies that have demonstrated the manner in which superior entrepreneurial ecosystems enable the creation of enterprise quality and the construction of competitive values at the regional level (Fritsch, 2013; Tsvetkova, 2015).

An Entrepreneurial Ecosystem Model for Developing Local Competitive Advantage based on the Network Theory Perspective. The entrepreneurial ecosystem consists of elements that interact with extreme complexity and independence (Isenberg, D, 2011). The entrepreneurial ecosystem is a dynamic economic model that can be used for the strategic planning process, for the provision of a framework for mutual relationships among participating stakeholders, and for the definition of customer needs. In the future, this exemplar can ensure in the enhancement of value propositions (Inga Erina, Vladimir Shatrevich, \& Elina Gaile-Sarkane, 2017).

The main study model of entrepreneurial ecosystems is the one proposed by Isenberg $(2011 ; 2013)$. It features six interrelated areas that describe the functions of the network components (Diego Alex Gazaro dos Santos, Aurora Carneiro Zen, \& Vitor Klein Schmidt, 2017). These domains are outlined below.

1. Policy: The government's role in removing barriers and in providing ideal preconditions for the development of entrepreneurship must be emphasized (Isenberg, 2011; Mason \& Brown, 2014). This precondition relates to reforms in the legal framework, the bureaucracy, and the regulations pertaining to the business environment (Cohen, 2006; Isenberg, 2010).

2. Access to finance: Entrepreneurs see this factor as one of three key aspects of the entrepreneurial ecosystem, the other two being markets and human resources (WEF, 2013). Financial resources, whether public or private, should be made available, visible, and accessible to all segments and sectors of the ecosystem (Stam, 2015).

3. Culture: This domain refers to the strengthening of informal institutions for employers and also contributes significantly to the evolution of ecosystems. Successful entrepreneurs are often those who have failed one or more times before flourishing (Isenberg, 2010; 2011).

4. Supporting services: This area is divided into the three principal categories of infrastructure, non-governmental organizations, and supporting professions. Nongovernmental organizations include accelerators, hubs, and incubators (Arruda et al., 2015). Supporting professions include services such as assistance in business legalization, 
corporate lawyers, accountants, consultants, suppliers, and funding agencies (Isenberg, 2011).

5. Human capital: Companies that want to succeed require skilled workers. In the absence of readily available human capital, entrepreneurship education can provide the necessary support for training people in the requisite skill sets (Isenberg, 2013).

6. Markets: Two elements make a considerable contribution to the capacity of new businesses in accessing the opportunities offered by the market. The first constituent is a large company that provides the necessary resources, space, and commercial opportunities in the form of the first contract or the initial customer. The second ingredient is the network, which represents a major source of information, resources, and access to domestic and international markets (Zahra, Wright, \& Abdelgawad, 2014).

How, then, do these components of the entrepreneurial ecosystem interact? The entrepreneurial ecosystem is dynamic; an understanding of it can allow for the exploitation of the potential of the system (and system theory) and demonstrate how the design of the system can be aligned with other available concepts that affect competitive advantage, such as innovation networks and knowledge groups. As an arrangement that is rich in information and knowledge, the entrepreneurial ecosystem contains "connecting assets" that serve to link people, ideas, and resources (Napier \& Hansen, 2011). These connecting assets may be clearly defined as extensively networked and experienced business people who command the skills, knowledge, and associations with people and resources to support the new company. By sharing expertise, information, and resources and by connecting start-ups with appropriate individuals and organizations (e.g., customers, service providers, and talents), these connecting assets can help new companies realize their growth potential. The connector may be an entrepreneur, an investor, or a service provider (Mason \& Brown, 2014).

This paper utilizes network theory to observe the relationships and interactions of the actors and the factors that form the networks within the entrepreneurial ecosystem. The conceptual framework and entrepreneurial ecosystem model developed by the present research initiative is informed by previous models introduced by Isenberg (2011), Mason and Brown (2014), and Erik Stam (2015). The theoretical grounding for model development rests in the viewpoint that the entrepreneurial ecosystem represents a set of interrelated and informally coordinated actors that interconnect, mediate, and manage entrepreneurial performance within the local entrepreneurial environment. The aim of the proposed model is to assist entrepreneurial success through all stages of the process, to aid the creation of new businesses, and to help the development of existing enterprises. Ultimately, the objective of the posited model is to generate productive entrepreneurship and to improve the competitive advantage of a company, a region, or a nation (Isenberg, 2011; Clarysse et al., 2014, Mason \& Brown, 2014; Stam, 2015). The existing actors and the components of the systemic factors are embodied in several variables in the entrepreneurial ecosystem. At least six genres of actors and five systemic factors are involved in the conceptual framework of the entrepreneurial ecosystem model. The variables of competitive advantage comprise four indicators: valuable, rare, difficult to replicate, and organization (Barney, 2001).

The relational structure between different stakeholders in the entrepreneurial ecosystem is implicit in the perspective of network theory. Social network connectivity is influenced by the levels of relatedness between employers, government agencies, incubators, or members of accelerator organizations, and investors or constituents of higher education organizations (Xaver Neumeyer \& Susana C. Santos, 2017). The associations are interrelated to achieve the common goal of forming a path that indirectly connects the unconnected or directly bound actors/factors. The bond pattern of the network produces a certain structure, and the actor/factor occupies a position within this structure. Most analyses using network theory assess the characteristics of a network structure and its actor/factor positions (centrality). In doing so, they attempt to relate the centrality or the positioning of individual actors/factors and/or grouped components to the achievements and outputs generated by them (Boggati \& Halgin, 2011). 


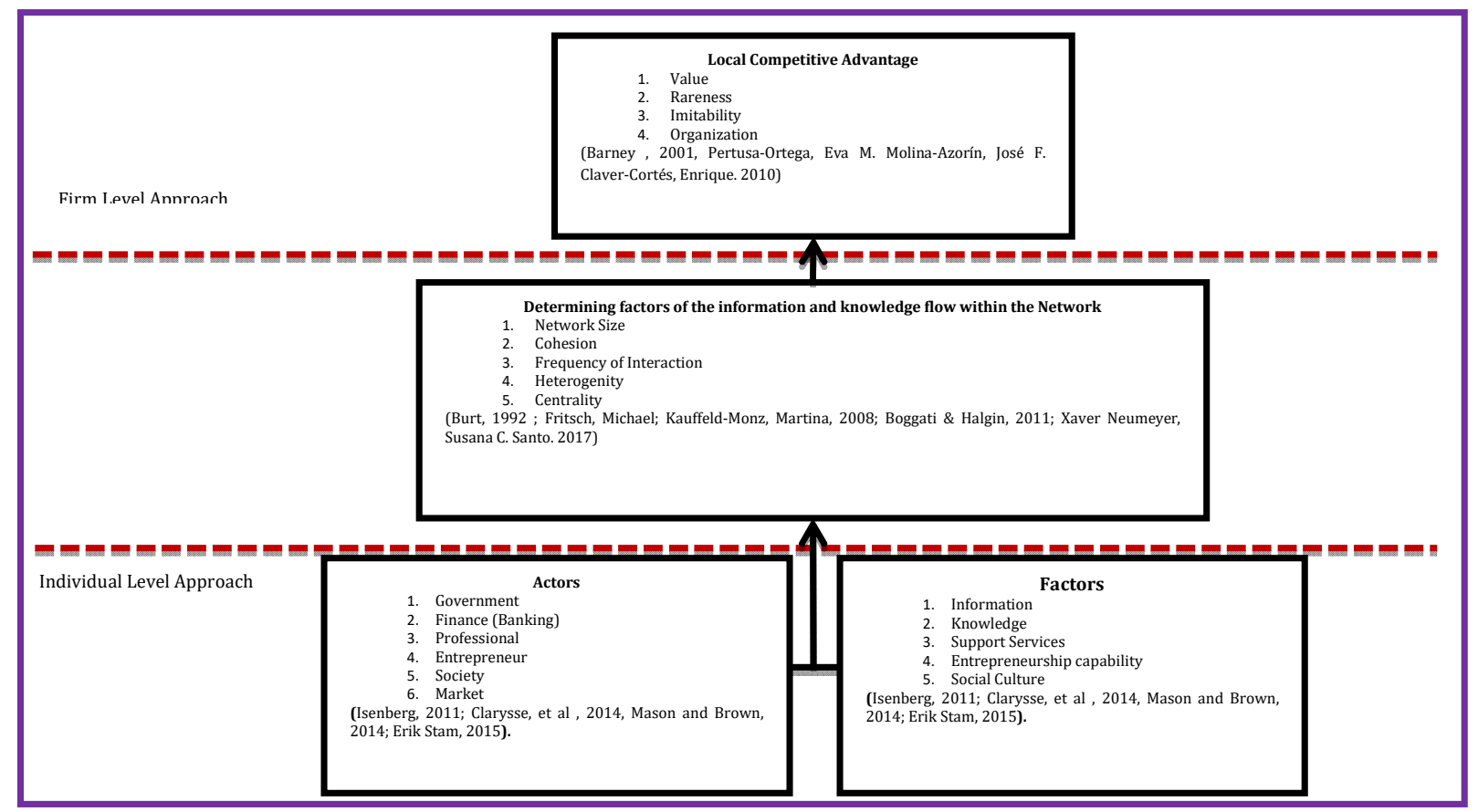

Figure 2 - Conceptual Framework of Entrepreneurship Ecosystems Based on the Network Theory Perspective (Sources: Modified by the author based on Xaver Neumeyer, Susana C. Santo, 2017)

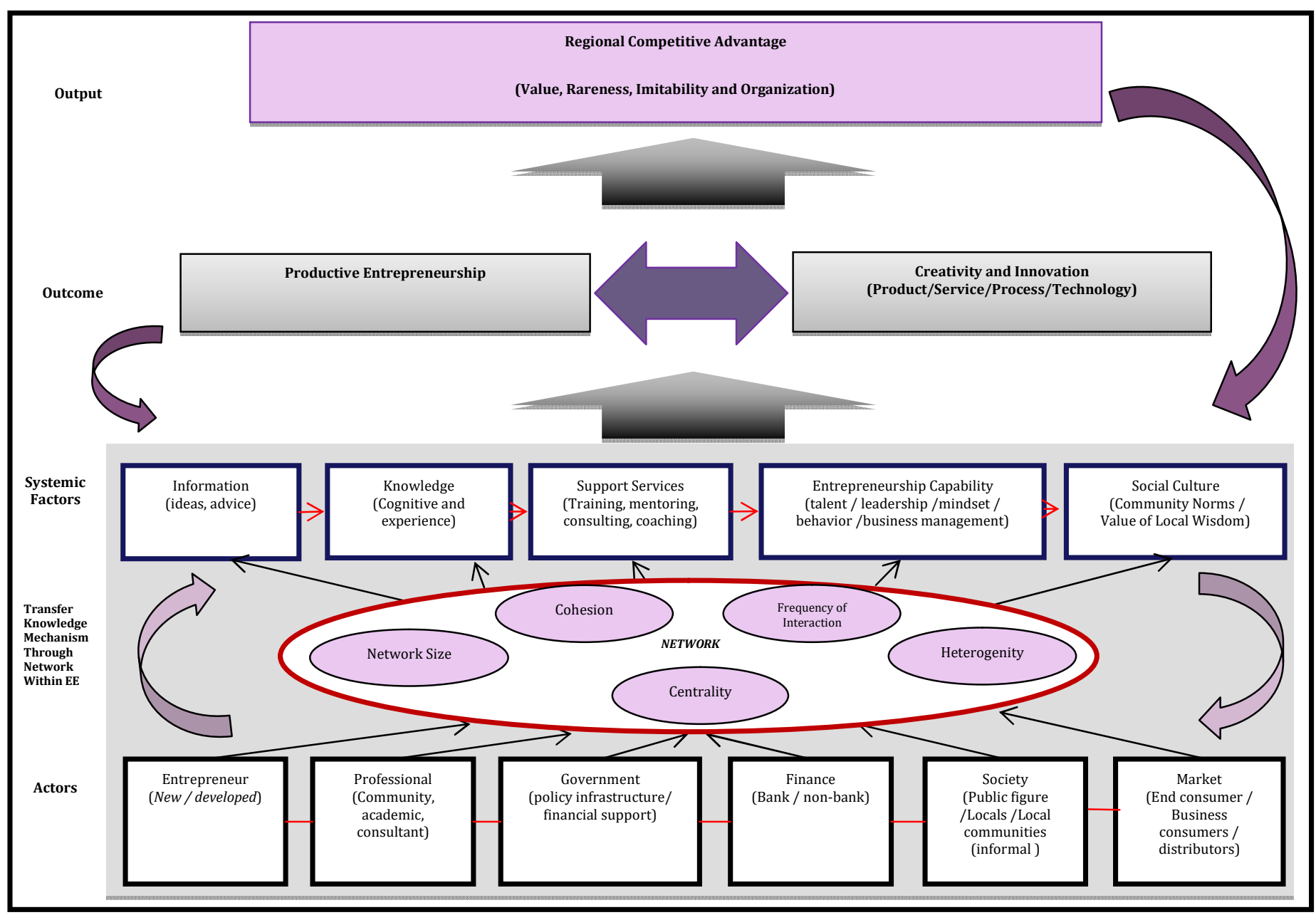

Figure 3 - Entrepreneurial Ecosystems Model (Source: Modified by the author based on Burt, 2001; Isenberg, 2011; Clarysse, et al, 2014,; Mason and Brown, 2014; Erik Stam, 2015) 
This article refers to the Flow Model based Structural Holes Theory (Burt, 1992), which was later modified to include the indicators of network size, cohesion, heterogeneity, frequency of interaction, and centrality (Hanneman, Robert, A. \& Mark Riddle, 2005; Fritsch, Michael, Kauffeld-Monz, \& Martina, 2008; Xaver Neumeyer \& Susana C. Santos., 2017).

The conceptual framework and model describing the impact of an entrepreneurial ecosystem on regional competitive advantage is outlined in Figure 2.

Figure 3 illustrates the interactions in the context of knowledge transfer between all the elements that exist within the entrepreneurial ecosystem. On the basis of network theory, this model of the entrepreneurial ecosystem can exhibit the ways in which each component of the entrepreneurial ecosystem interacts through a framework that can show the size of the network, its cohesion, its heterogeneity, the frequency of the interactions, and centrality of all the actors within the entrepreneurial ecosystem. Using this measure, an analysis can be performed on the relationships and functions of each actor or factor, the network density, the frequency of interactions, the strengths or weaknesses of the actors/factors or their relationships, the most dominant actors/factors, the connecting actors/ factors, and the diversity of the actors/factors within the entrepreneurial ecosystem. In the context of knowledge transfer, the results of the analysis of these indicators will assist in the designing of policies and strategies related to the formulation of training programs, business coaching, financial plans, marketing schemes, and other aspects. Such policies and strategies may further be directed at increasing productive entrepreneurship to produce innovative, creative, and value-added new products/services that will positively influence the region's competitive advantage. The associations between discrete domain specializations can be established through the network and these connections are dependent on the interactions of social capital and the knowledge transfers between key stakeholders (Hayter, 2013; Adao Flores, Elsa Pereira, \& Henrique Graca, 2017).

According to Chesbrough (2003), a company is geared toward an open innovation paradigm to tackle increasingly complex and uncertain environmental challenges. Hence, valuable ideas can come from within or from outside the organizational boundaries and then proceed to the market from within or from outside the company. In this context, entrepreneurial ecosystems are environments that encourage open innovation (Diego Alex Gazaro dos Santos, Aurora Carneiro Zen, \& Vitor Klein Schmidt, 2017), which usually occurs through entrepreneurial action via a set of interacting elements. An entrepreneurial ecosystem is the outcome of the interactions between actors who evolve together and who reinforce each other (Isenberg, 2011; Diego Alex Gazaro dos Santos, Aurora Carneiro Zen, \& Vitor Klein Schmidt, 2017). The entrepreneurial ecosystem seeks to create conditions that are ideal for the success and the sustainability of entrepreneurship. When it is well developed, this environment stimulates the growth of new companies and is essential for the formation and the expansion of innovative enterprises (Autio et al., 2014). More, the entrepreneurial ecosystem approach underlines the relationships between entrepreneurs and the environment within which they function (Diego Alex Gazaro dos Santos, Aurora Carneiro Zen, \& Vitor Klein Schmidt, 2017).

The vast and rich interfaces and interconnections between stakeholders working together in every emerging regional economy are signifiers of a complex and dynamic economic ecosystem. A successful ecosystem is presaged by the identification of the specific competencies of each stakeholder. The best aptitude sets are those that can create the highest value for other stakeholders (Krueger, N., 2012). Notably, the ability to encourage every actor in the environment is evidenced by the willingness of members to perform actions that can optimize value for the entire entrepreneurial ecosystem. Porter (p. 40, PA Consulting Group, 1990) argues that competitiveness is a function of dynamic progression, innovation, the capability to change, and the ability to increase value. An entrepreneurial ecosystem that can enliven innovation provides additional worth that creates further impact on competitive advantage and that can ultimately lead to the sustainability of the entrepreneurial ecosystem. This phenomenon holds because regional competitive advantage may be gained from knowledge and innovation (Porter, 2001; Carayannis and Campbell, 2011). 


\section{Conclusion:}

Growing scholarly attention is currently being attracted to the concepts of entrepreneurial ecosystems and competitive advantage. This paper has presented theories and arguments along with the proposition that the entrepreneurial ecosystem can play a critical role in the creation of competitive advantage for a particular region. In addition, the paper posits a conceptual model to demonstrate that entrepreneurial ecosystems can influence regional competitive advantage through mechanisms such as knowledge transfer, productive entrepreneurship, and innovation systems.

Implications for Policy Makers and Practitioners. Gaining an understanding of the unique and differentiated conditions of entrepreneurial ecosystems that grow in particular locations will aid policy makers and practitioners in making effective and efficient policies and strategies. Voelker (2012) argues that regardless of the economic and cultural characteristics of a particular local system, the entrepreneurial ecosystem must be designed in a manner that is aligned with local political and policy situations, incorporating actions in the key identified areas of culture, human resources, markets, finance, and support. Policy makers, entrepreneurial supporters, and business owners should take into account the nature of the locally structured entrepreneurial network. It would thus be effective to communicate with entrepreneurs within the local scope (Motoyama, Y., Konczal, J., Bell-Masterson, \& Jand Morelix, A, 2014). One of the objectives of good policy is to redesign the institution in such a way that it can attract entrepreneurial activity to progress in a favorable direction (W. J. Baumol \& R. J. Strom, 2007; Akbas, M.I., Gunaratne, C., Garibay, O.O., Garibay, I., and O'Neal, T, 2015). The outcomes of this research initiative will help policy makers and entrepreneurs advance toward constructive paths that will aid in the strengthening of networks, especially with regard to access to capital and markets, which represent the principal problems of entrepreneurship.

Directions for Future Research. Future research opportunities are indicated for empirical research to validate the model of entrepreneurial ecosystem proposed by this investigation. The nonlinear nature of many of the projected effects may pose a challenge to the testing of the posited relationships. The employment of dynamic system methods may be considered for the examination of causal relationships between the discrete elements that comprise the entrepreneurial ecosystem.

Alternatively, qualitative methods can also be utilized to scrutinize the relationships in terms of the characteristics discussed above. Qualitative data are also useful in describing the interactions between the actors and the factors within the entrepreneurial ecosystem. Finally, further research may be conducted to develop the model proposed in this paper, either with regard to the variables or with respect to other industrial sectors.

\section{REFERENCES}

1. Acs, Z.J., Estrin, S., Mickiewicz, T., and Szerb, L. (2017), "Institutions, entrepreneurship and growth: the role of national entrepreneurial ecosystems," papers.ssrn.com.

2. Acs, Z.J., Stam, E., Audretsch, D.B., and O'Connor, A. (2017), "The lineages of the entrepreneurial ecosystem approach," Small Business Economics, 49(1), 1-10.

3. Flores A., Pereira E., and Graca H., (2017), "Entrepreneurial Ecosystems" In Knowledge Transfer to and within Tourism, Emerald Publishing Limited, 8, pp. 97-111.

4. Adner, R., and Kapoor, R. (2010), "Value creation in innovation ecosystems: How the structure of technological interdependence affects firm performance in new technology generations," Strategic Management Journal, 31(3), 306-333.

5. Akbas, M.I., Gunaratne, C., Garibay, O.O., Garibay, I., and O'Neal, T. (2015), "Role of Entrepreneurial Support for Networking in Innovation Ecosystems: An Agent Based Approach," Proceedings of the 2015 Winter Simulation Conference.

6. Alberti, F.G., Giusti, J.D. and Pizzurno, E. (2016) "The role of institutions for collaboration in setting a competitive cluster ecosystem: the case of the French omega-3 cluster," Int. J. Competitiveness, 1(1), 4-32. 
7. Arina Romarina, (2016), "Economic Resilience Pada Indsutri Kreatif Guna Menghadapi Globalisasi Dalam Rangka Ketahanan nasional," Jurnal Ilmu Sosial, 15(1), 35-52.

8. Arruda, C., Nogueira, V. S., and Costa, V. (2013), "The Brazilian Entrepreneurial Ecosystem of Startups: an analysis of entrepreneurship determinants in Brazil as seen from the OECD pillars," Journal of Entrepreneurship and Innovation Management, 2(3), 17-57

9. Audretsch, D.B. and Pena-Legazkue, I. (2012), "Entrepreneurial activity and regional competitiveness: an introduction to the special issue," Small Business Economics, 39(3), 531-537.

10. Auerswald, Philip E. (2015), "Enabling Entrepreneurial Ecosystems: Insights from Ecology to Inform Effective Entrepreneurship Policy."

11. Autio, E., Kenney, M., Mustar, P., Siegel, D. and Wright, M. (2014), "Entrepreneurial innovation: The importance of context," Res Policy, 43(7), 1097-1108.

12. Barney, Jay, (2001), "Is the resource based "view" a useful perspective for strategic management research? Yes," Academic of Management Review, 26(1), 41-56.

13. Boggati, Stephen P \& Halgi, Daniel S. (2011), "on Network Theory," Organization Science, 22(5), 1168-1181.

14. Burt, R. S. (1992), "Structural Holes: The Social Structure of Competition," Harvard University Press.

15. Brown and Mason, (2017), "Looking inside the spiky bits: a critical review and conceptualisation of entrepreneurial ecosystems," Small Business Economics, 49(1), 1130.

16. Carayannis E.G., and Campbell D.F.J. (2011), "Open Innovation Diplomacy and a 21st Century Fractal Research, Education and Innovation (FREIE) Ecosystem: Building on the Quadruple and Quintuple Helix Innovation Concepts and the 'Mode 3' Knowledge Production System," J Knowl Econ, 2:327-372.

17. Clarysse, Bart, Wright, M., Bruneel, J. and Mahajan, A., (2014), "Creating Value In Ecosystems: Crossing The Chasm Between Knowledge and Business Ecosystems," Research Policy, 43(7), 1164-1176.

18. Carree M.A., Thurik A.R. (2010), The Impact of Entrepreneurship on Economic Growth. In: Acs Z., Audretsch D. (eds) Handbook of Entrepreneurship Research. International Handbook Series on Entrepreneurship, vol 5. Springer, New York, NY.

19. Cooke, P. (2016), "The virtues of variety in regional innovation systems and entrepreneurial ecosystems," Journal of Open Innovation: Technology, Market, and Complexity, 2(1):13.

20. Diego Alex Gazaro dos Santos, Aurora Carneiro Zen, and Vitor Klein Schmidt. (2017), "Entrepreneurship Ecosystems and the Stimulus to the Creation of Innovative Business: A Case in the App Industry in Brazil," Journal of Research in Business, Economics and Management, 8(5).

21. Dubina, I. N., Gallardo-Vázquez, D., Sánchez-Hernández, M.I. and del Consuelo RuizRodríguez, M.,. (2017), "The Balanced Development of the Spatial Innovation and Entrepreneurial Ecosystem Based on Principles of the Systems Compromise: A Conceptual Framework," J Knowl Eco, 8(2), 438-455.

22. F. Castilla-Polo, Gallardo-Vázquez, D., Sánchez-Hernández, M.I. and del Consuelo RuizRodríguez, M.,, (2017), "Cooperatives as Responsible and Innovative Entrepreneurial Ecosystems in Smart Territories: The Olive Oil Industry in the South of Spain," Handbook of Research on Entrepreneurial Development and Innovation Within Smart Cities, pp. 459-490.

23. Michael. F., Martina K. M. (2008), "The impact of network structure on knowledge transfer: an application of social network analysis in the context of regional innovation networks," Jena economic research papers, No. 2008,036

24. Gonzalez-Pernia, J.L., Pena-Legazkue, I., and Vendrell-Herrero, F. (2012), "Innovation, entrepreneurial activity and competitiveness at a sub-national level," Small Business Economics,39(3), 561-574 
25. Guerrero, M., Urbano, D., and Fayolle, A. (2014), "Entrepreneurial activity and regional competitiveness: evidence from European entrepreneurial universities," J Technol Transf. 41(1), 105-131.

26. Hanneman, Robert A. and Mark Riddle. (2005), "Introduction to social network methods. Riverside," CA: University of California, Riverside, January 2005.

27. Huggins, Robert. (2013), "Regional Competitiveness: Theories and Methodologies for Empirical Analysis," JCC: The Business and Economics Research Journal, 6(2), 155-172

28. Iansiti, M., \& Levien, R. (2004), "The keystone advantage: what the new dynamics of business ecosystems mean for strategy, innovation, and sustainability." Cambridge: Harvard Business Press.

29. Inga Erina, Vladimir Shatrevich and Elina Gaile-Sarkane, (2017), "Impact of stakeholder groups on development of a regional entrepreneurial ecosystem," European Planning Studies, 25(5) 755-771.

30. Isenberg, Daniel. (2010), "The Big Idea: How to Start an Entrepreneurial Revolution," Harvard Business Review. 88(6), 40.

31. Isenberg, D. (2011), "The entrepreneurship ecosystem strategy as a new paradigm for economic policy: principles for cultivating entrepreneurship," Institute of International European Affairs, Dublin.

32. Jennen, Tina. (2016), "Stakeolder Engagement in the Creation of an Entrepreneurial Ecosystem," Journal of Asia Entrepreneurship and Sustainability, 12(1).

33. JinHyo Joseph Yun, DongKyu Won, KyungBae Park, JeongHo Yang and Xiaofei Zhao, (2017), "Growth of a platform business model as an entrepreneurial ecosystem and its effects on regional development," European Planning Studies, 25(5), 805-826.

34. Krammer, Sorin M. S. (2017), "Science, technology, and innovation for economic competitiveness: The role of smart specialization in less-developed countries," Technological Forecasting and Social Change, https://www.sciencedirect.com/science/article/pii/S0040162517308582

35. Krueger, N. (2012), "Bridging town and gown: best practice? An essay on growing the local entrepreneurial ecosystem," Int. J. Business and Globalisation, 9(4),347-358.

36. Letaifa et al., (2016), "The role of social platforms in transforming service ecosystems," Journal of Business Research, 69,1933-1938

37. Liao, Shu-Hsien et al. (2016), "Developing a Sustainable Competitive Advantage: Absortive Capacity, Knowledge Transfer and Organizational Learning," Springer Science Business Media New york.

38. Mack, E. and Mayer, H. (2016), "The evolutionary dynamics of entrepreneurial ecosystems," Urban Studies, 53(10), 118-2133.

39. Malecki, E.J. (2011), "Connecting local entrepreneurial ecosystems to global innovation networks: open innovation, double networks and knowledge integration," International Journal Entrepreneurship and Innovation Management, 14(1), 36-59.

40. Mason and Brown. (2014), "Entrepreneurial ecosystems and growth oriented entrepreneurship," Background paper prepared for the workshop organised by the OECD LEED Programme and the Dutch Ministry of Economic Affairs on Entrepreneurial Ecosystems and Growth Oriented Entrepreneurship, The Hague, Netherlands.

41. Mike Raco. (1999), "Competition, Collaboration and the New Industrial Districts: Examining the Institutional Turn in Local Economic Development," Urban Studies, Vol. 36, Nos $5 \pm 6,951 \pm 968,1999$

42. M. Kabbaj, et al. (2016), "A study of the social entrepreneurship ecosystem: The case of Morocco," Journal of Developmental Entrepreneurship.21(4).

43. M. Teresa Fernandez Fernandez, Francisco J. Blanco Jimenez and Juan R. Cuadrado Roura, (2015), " Business incubation: innovative services in an entrepreneurship ecosystem," The Service Industries Journal, 35:14.

44. Moore, J.F. (1993), "Predators and prey: a new ecology of competition," Harvard Business Review,71(3), 75-83

45. Motoyama, Y., et al (2014), "Think Locally, Act Locally: Building a Robust Entrepreneurial Ecosystem," The Ewing Marion Kauffman Foundation. 
46. Nasir and Yuslinaini, (2017), "Analisis Pemetaan Industri Kreatif Subsektor Kerajinan Serta Dampak Peningkatkan Kesejahteraan Masyarakat di Kabupaten Aceh Besar," Jurnal Ekonomi and Manajemen Teknologi, 1(1), 11-17

47. Napier, G and Hansen, C. "(2011) Ecosystems for Young Scaleable Firms," FORA Group.

48. Nicotra M., Romano M., Del Giudice M., Schillaci E. C. (2017), "The causal relation between entrepreneurial ecosystem and productive entrepreneurship: a measurement framework," J Technol Transf.

49. Pertusa-Ortega, Eva M. Molina-Azorin, Jose F. Claver-Cortes, Enrique. (2010), "Competitive strategy, structure and firm performance A comparison of the resourcebased view and the contingency approach," Management Decision, 48(8), 1282-1303

50. Pitelis, C. (2012), "Clusters, entrepreneurial ecosystem co-creation, and appropriability: a conceptual framework," Industrial and Corporate Change,21 (6)1359-1388.

51. Porter, M. (1990), "The Competitive Advantage of Nations," Basingstoke, Macmillan, U.S.A

52. R. Agarwal, D. Audretsch, and M. Sarkar, (2010), "Knowledge Spillovers and Strategic Entrepreneurship," Strat. Entrepreneurship J., 4: 271-283.

53. Rodriguez, E Soto. (2015), "Entrepreneurial ecosystems as a pathway towards competitiveness: The case of puerto rico," JCS, 23 (1\&2), 2015.

54. Huggins, Robert and Williams, Nick, (2011), "Entrepreneurship and regional competitiveness: The role and progression of policy," Entrepreneurship \& Regional Development: An International Journal, 23:9-10, 907-932

55. Roundy, Philip T. (2017) "Social entrepreneurship and entrepreneurial ecosystems: Complementary or disjoint phenomena?," International Journal of Social Economics, 44(9)1252-1267

56. Stam, E and Bosma, N. (2015), "Growing entrepreneurial economies: Entrepreneurship and regional development," The Routledge Companion to Entrepreneurship, Baker, T. \& Welter, F. (eds)..

57. Stam. (2015), "Entrepreneurial ecosystems and regional policy: A sympathetic critique," Discussion Paper Series 15-07. Utrecht School of Economics. Tjalling C. Koopmans Research Institute

58. Starr, M.A. (2014), "Qualitative and mixed-methods research in economics: surprising growth, promising future," Journal of Economic Surveys, 28(2) 238-264.

59. Szerb, Laszlo., Lafuente, Esteban., Horvath, Krisztina., and Pager, Balazs. (2017), "The relevance of quantity and quality entrepreneurship for regional performance: The moderating role of the entrepreneurial ecosystem," SSRN Electronic Journal

60. Terjesen, S., Acs, Z. J., Audretsch, D. B., Hechavarria, D., Stam, E., and White, R. (2017) Entrepreneurial ecosystems: the search for performance, University of Tampa, unpublished.

61. T. Sadek, Kleiman R., Loutfy R. (2015), "The role of technology transfer offices in growing new entrepreneurial ecosystems around mid-sized universities," International Journal Innovation and Regional Development, 6(1).

62. Tsvetkova, A. (2015), "Innovation, entrepreneurship, and metropolitan economic performance: Empirical test of recent theoretical propositions," Economic Development Quarterly 29(4):299-316

63. Voelker, Troy A. (2012), "Entrepreneurial ecosystems: evolutionary paths or differentiated systems?," Business Studies Journal,4(2).

64. Xaver Neumeyer, Susana C. Santo. (2017), "Sustainable business models, venture typologies, and entrepreneurial ecosystems: A social network perspective," Journal of Cleaner Production.

65. Yagoub, Entezari. (2015), "Building Knowledge- Based Entrepreneurship Ecosystems: Case of Iran," Procedia - Social and Behavioral Sciences, 195, 1206 - 1215

66. Zahra, S.A. and Nambisan, S. (2012), "Entrepreneurship and strategic thinking in business ecosystems," Business Horizons, 55(3), 219-229. 